\title{
Isolation and Culture of Neonatal Murine Primary Cardiomyocytes
}

\author{
Venkatraman Ravi, ${ }^{1,4}$ Aditi Jain, ${ }^{2,4}$ Arushi Taneja, ${ }^{1}$ Kaushik Chatterjee, ${ }^{2,3}$ \\ and Nagalingam Ravi Sundaresan ${ }^{1,5}$ \\ ${ }^{1}$ Cardiovascular and Muscle Research Laboratory, Department of Microbiology and Cell \\ Biology, Indian Institute of Science, Bengaluru, India \\ ${ }^{2}$ Centre for BioSystems Science and Engineering, Indian Institute of Science, Bengaluru, \\ India \\ ${ }^{3}$ Department of Materials Engineering, Indian Institute of Science, Bengaluru, India \\ ${ }^{4}$ These authors contributed equally to this work. \\ ${ }^{5}$ Corresponding author: rsundaresan@iisc.ac.in
}

\begin{abstract}
The cardiomyocyte is the main cell type in the heart responsible for its contractile function. Culturing primary cardiomyocytes from mammalian sources to study their function remains challenging as they are terminally differentiated and cease to multiply soon after birth. The major technical hurdles associated with primary cardiomyocyte culture include attaining high yields, obtaining healthy/viable cells that show spontaneous contractions upon culture, and avoiding contamination by non-myocyte cardiac cell types such as fibroblasts and endothelial cells. The yield and the quality of the cardiomyocytes obtained are impacted by a variety of factors, such as the purity of the reagents, composition of the digestion mixture, the digestion conditions, and the temperature of the tissue during different steps of isolation. Here, we provide a simplified workflow to isolate, culture, and maintain neonatal primary cardiomyocytes from rats/mice in culture dishes, which can then be used to study, for instance, cardiac hypertrophy and drug-induced cardiotoxicity. () 2021 Wiley Periodicals LLC.
\end{abstract}

Basic Protocol: Isolation and culture of primary cardiomyocytes from rat/mouse pups

Support Protocol: Coating of tissue culture plates with extracellular matrix substrates for efficient cardiomyocyte attachment

Keywords: cardiomyocytes $\bullet$ cardiac hypertrophy $\bullet$ cardiotoxicity $\bullet$ doxorubicin - primary culture

\section{How to cite this article:}

Ravi, V., Jain, A., Taneja, A., Chatterjee, K., \& Sundaresan, N. R. (2021). Isolation and culture of neonatal murine primary cardiomyocytes. Current Protocols, 1, e196. doi: 10.1002/cpz1.196

\section{INTRODUCTION}

Cardiac muscle cells, or cardiomyocytes, are striated muscle cells that form the basic unit of the contractile apparatus of the heart. Defects in cardiomyocyte function result in a variety of cardiac pathologies, such as cardiac hypertrophy, arrhythmias, and cardiomyopathies, which can lead to heart failure and, ultimately, death. Moreover, cardiomyocytes are frequently the unintended targets of chemotherapeutic drugs such as anthracyclines, which can result in significant cardiac damage (Volkova \& Russell, 2011). Therefore, understanding the mechanisms underlying cardiac pathologies and 
drug-induced cardiotoxicity is of paramount importance to devise strategies to prevent heart failure and death.

Cultured neonatal primary cardiomyocytes from rat and mouse represent an immensely useful model system to study various cellular and sub-cellular aspects of cardiomyocyte physiology, such as its morphology, gene-expression profiles, cellular signaling, cell mechanics, calcium fluxes, and electrophysiological changes (Jacot, McCulloch, \& Omens, 2008; Jain, Ravi, Muhamed, Chatterjee, \& Sundaresan, 2017). Isolated cardiomyocytes recapitulate multiple aspects of the in vivo physiology of the native cardiomyocytes (Louch, Sheehan, \& Wolska, 2011) and are sufficiently pure to allow studies on a homogeneous population of cells without interference from other cardiac cell types or systemic influences present in a live animal, making it highly suitable for mechanistic studies. Furthermore, various disease conditions such as cardiac hypertrophy can be simulated in vitro using cultured cardiomyocytes by treating them with appropriate agents such as isoproterenol, phenylephrine, or angiotensin II (Miyata \& Haneda, 1994; Ravi et al., 2018). In addition, cultured cardiomyocytes also offer a facile platform for the high-throughput screening and evaluation of various gene/drug candidates and their toxicity profiles (Jentzsch et al., 2012; Reid et al., 2016; Wells et al., 2019).

Studies as the ones described above require a pure population of high-quality cardiomyocytes, that is, cells that are healthy, undamaged, and are functionally active, exhibiting spontaneous contractions. Obtaining viable high-quality cardiomyocytes in sufficient numbers for these analyses, however, has been challenging due to the non-proliferative nature of these cells. Moreover, cardiomyocytes exist alongside diverse cell types such as fibroblasts and endothelial cells in the heart, embedded in a complex extracellular matrix environment, and hence, obtaining pure cultures can be difficult. Attempts to isolate cardiomyocytes, thus, typically involve steps to dissociate the cardiac tissue into individual cells by digesting the extracellular matrix using specific enzymes and then, specifically enriching for cardiomyocytes. All of these steps, however, need to be performed while ensuring minimal stress to the cardiomyocytes which otherwise would drastically compromise the viability and function of the isolated cells.

Isolation and culture of cardiomyocytes has been described from both neonatal and adult murine animals, though neonatal cultures are relatively easier to set and maintain, as they do not require specialized apparatus, which makes this also more cost-effective. Moreover, the neonatal cardiomyocytes are amenable to routine non-viral gene transfer methods such as lipofection, which make their genetic manipulation easier compared to adult cardiomyocytes, which are refractory to lipofection (Louch et al., 2011). These distinct advantages make neonatal murine cardiomyocyte cultures a widely preferred model for in vitro studies on cardiomyocyte physiology and pathology.

Here, we provide a detailed step-by-step protocol for the successful isolation and maintenance of cardiomyocytes from neonatal rat/mouse using minimal reagents and in a time-effective manner (Basic Protocol). The protocol involves digestion of minced heart tissues using an enzymatic mixture of trypsin and collagenase type II in the presence of mechanical agitation, which ensures efficient digestion of the tissue to produce a high yield of viable cardiomyocytes. Notably, the protocol employs short, repeated cycles of digestion to reduce stress on cells and enhance viability. Finally, the cardiomyocytes are selectively enriched through a pre-plating procedure, which helps get rid of contaminating non-myocyte cardiac cells such as fibroblasts and endothelial cells. In addition, we also describe the procedures for coating the culture dishes with extra-cellular matrix proteins to aid the attachment of cardiomyocytes (Support Protocol). 
The cardiomyocytes isolated and cultured using the method described here can be used for diverse studies, including investigations on cardiomyocyte physiology, mechanisms underlying disease, drug-screens, and to evaluate for drug-induced cardiotoxicity.

\section{ISOLATION AND CULTURE OF PRIMARY CARDIOMYOCYTES FROM MOUSE/RAT PUPS}

Here, we describe a simple procedure for isolation and culture of cardiomyocytes from neonatal rat/mouse, which is based on our previous publication (Jain et al., 2017). The method employs two commonly used enzymes, trypsin and collagenase type II, for digestion of heart tissues, and does not require the use of any growth supplements or specialized media for culturing the cardiomyocytes. Moreover, the entire procedure can be completed in less than $4 \mathrm{hr}$. The major steps involved in the procedure include the dissection of the animal, harvesting of the heart, mincing of the heart, enzymatic digestion of the heart tissue, collection of dissociated cells, enrichment of cardiomyocytes, and finally, culturing them on tissue culture plates (Fig. 1). The steps described here are common to both rat and mouse pups, and any differences in the amount of reagents used are indicated at the appropriate steps.

Before beginning the procedure, we advise users to consult the institutional guidelines on the use of animals in experiments and also to obtain the necessary approval from the relevant animal ethics committees. Always wear sterile gloves and lab coat while handling animals and avoid any direct contact with animals or their tissues. Collect animal carcasses and tissue waste generated during the experiments separately, seal them in double bags, and dispose of them preferably by incineration and adhering to institutional/local guidelines.

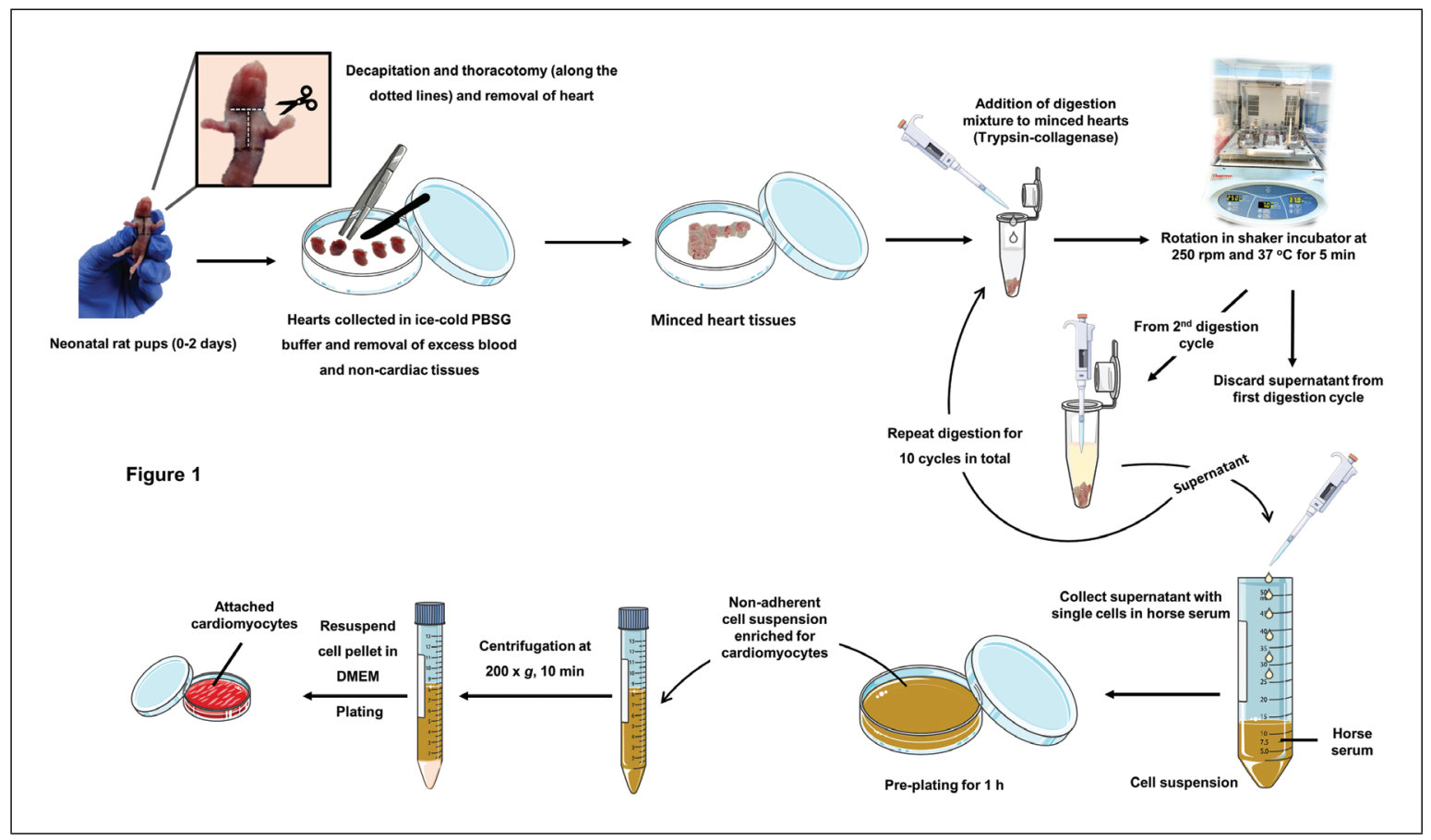

Figure 1 Schematic diagram depicting the major steps in the isolation and maintenance of cardiomyocytes from neonatal murine animals as described in the Basic Protocol. See text for details. This figure was created with images adapted from Servier Medical Art by Servier. Original images are licensed under a Creative Commons Attribution 3.0 Unported License. 


\section{Materials}

Rat/mouse pups (0-2 days old, 1 rat pup or 4 mouse pups for obtaining $\sim 10^{6}$ cardiomyocytes)

$70 \%(\mathrm{w} / \mathrm{w})$ ethanol (in double-distilled water)

Lukewarm distilled water

$1 \times$ PBSG (phosphate-buffered saline with D-glucose) buffer (see recipe)

Digestion mixture (DM: see recipe)

Horse serum (Gibco, cat. no. 16050122)

DMEM culture medium supplemented with $10 \%$ FBS and antibiotic-antimycotic mix (see recipe)

BrdU stock solution (see recipe), optional

Sterile absorbent cotton

Sterile dissection hood

Surgical scissors

Dissection table

100-mm cell culture dishes, sterile

Forceps

Surgical blades

Microcentrifuge tubes

Orbital shaker incubator (Thermo MAXQ 4450)

Vortex mixer

Benchtop microcentrifuge

50-ml Falcon conical centrifuge tubes

Tissue culture $\mathrm{CO}_{2}$ incubator $\left(37^{\circ} \mathrm{C}\right.$ and $\left.5 \% \mathrm{CO}_{2}\right)$

Hemacytometer

Coated tissue culture plates (see Support Protocol)

\section{Harvesting heart tissue}

1. Use a cotton ball to wipe each rat/mouse pup gently but thoroughly, first with lukewarm water and then with $70 \%$ ethanol, to remove dirt or any contaminants.

This is a crucial step to try to eliminate most contamination due to environmental factors. Avoid using $100 \%$ ethanol, as it can dehydrate the animal's skin.

The number of pups required for the culture should be calculated based on the requirements of the experiment. Following this protocol, about $10^{6}$ cardiomyocytes are obtained per rat heart or per four mice hearts.

Perform steps 2-4 inside a sterile dissection hood.

2. Anesthetize the pups and euthanize the animals by decapitation using a pair of sterile scissors and according to your institution's approved protocols.

The pups used should be between 0 and 2 days old. Older pups result in a poorer yield of viable cells.

Sterilize the scissors by wiping them with $70 \%$ ethanol after sacrificing each animal and before reusing them.

The animals should be euthanized strictly adhering to institutional/national guidelines and after obtaining due approval from relevant animal ethics committees. We refer the user to articles describing methods available for anesthetization and euthanasia (Donovan \& Brown, 2005; Shomer et al., 2020) to make an appropriate choice based on suitability, convenience, and applicable local regulations.

3. Hold the animal in the supine position on a clean dissection table and make an incision above the thorax region, cutting through the ribs using a pair of sterile surgical scissors, to expose the heart. 
Use a separate pair of scissors for decapitation and dissection. Sterilize the scissors by wiping them with $70 \%$ ethanol after using them.

4. Quickly excise the heart using a fresh pair of sterile scissors and immerse the heart immediately in a dish with ice-cold, sterile PBSG buffer.

To access the heart tissue, hold the animal in between the ring and index finger, and give a gentle push from the rear side of the heart using the middle finger to protrude it out. It is critical to place the excised heart immediately in ice-cold buffer as it allows the heart's metabolism to slow down; thus, reducing stress on the heart.

All subsequent steps should be performed inside a sterile cell-culture hood and using sterile tools and reagents.

5. Transfer the heart to another dish containing fresh ice-cold PBSG buffer and squeeze it gently with the forceps to pump out any excess blood within the organ. Carefully remove any additional tissue attached to the heart, such as the lung tissues, diaphragm, and large blood vessels using the scissors. Also, carefully remove the atrial tissues leaving behind only the ventricles.

The atria are situated on top of the ventricles like a small flap and are relatively very small compared to the ventricles. Excise any tissues on top of the ventricles that contain the atria and any large blood vessels.

\section{Digestion of heart tissue}

6. Mince the heart into small chunks of $\sim 1 \mathrm{~mm}^{3}$ using a surgical blade or a fresh pair of scissors and pool the pieces in a microcentrifuge tube containing digestion mixture (DM) $(75 \mu \mathrm{l}$ per rat heart; $75 \mu \mathrm{l}$ per four mouse hearts).

Up to 4 rat hearts and 10-12 mouse hearts can be pooled into a single microcentrifuge tube; adjust the volume of DM accordingly.

Perform this step quickly without any delays to avoid cell death and to increase the yield of viable cardiomyocytes. Avoid grinding or crushing, as the use of excessive force results in cell death due to mechanical stress.

7. Begin digestion by transferring the tube containing the heart chunks in DM to a shaker incubator maintained at $37^{\circ} \mathrm{C}$ and with constant shaking at $250 \mathrm{rpm}$ for 5 min.

The temperature and shaking conditions are critical for high yield of viable cardiomyocytes. Excessive shaking can stress the cells, while sub-optimal shaking results in poor digestion.

8. Gently vortex the tubes and spin them very briefly for about $10 \mathrm{~s}$ to collect the tissue pieces at the bottom. Discard the supernatant.

The supernatant from the first round of digestion mostly contains erythrocytes and debris from extracellular material.

9. Add fresh DM (75 $\mu \mathrm{l}$ per rat heart; $75 \mu \mathrm{l}$ per four mouse hearts) to the Falcon tube and repeat digestion as in step 7. Give a gentle tap to disperse the tissue material inside before placing the tube back in the shaker incubator.

Avoid harsh/long vortexing as the use of excessive force can damage the cells.

10. At the end of the digestion, vortex the tubes gently and spin the tubes briefly for 10 s. Carefully collect the supernatant in a sterile $50-\mathrm{ml}$ Falcon conical centrifuge tube, leaving behind the undigested tissue. Add warm $\left(37^{\circ} \mathrm{C}\right)$ tissue culture grade horse serum ( $1.5 \mathrm{ml}$ per rat heart or $1.5 \mathrm{ml}$ per four mouse hearts) to the Falcon tube. Transfer the Falcon tube to an incubator maintained at $37^{\circ} \mathrm{C}$. 
The cells collected starting from this step should be maintained in a sterile environment to avoid any contamination. The Falcon tubes can be placed inside a regular tissue culture incubator maintained at $37^{\circ} \mathrm{C}$. Leave the screw caps of the Falcon tubes partially open (but not completely) to allow for the passage of air.

11. Repeat steps 9 and 10 for a total of ten rounds of digestion or until the tissue is completely digested (tissue mass disappears), whichever happens first. After each round of digestion, collect the supernatant in the same Falcon tube containing the horse serum and return it to the $37^{\circ} \mathrm{C}$ incubator.

The volume of horse serum used should be roughly double the volume of the supernatant collected from all the digestion steps put together. The horse serum neutralizes the enzymes in the DM and prevents over digestion, which can damage the cells. Horse serum is preferred over fetal bovine serum for this step as the former has fewer growth factors which slows down the growth of proliferating cells in the heart, such as the fibroblasts.

Though digestion above ten rounds can increase the cellular yield, extended digestion can damage the cells and reduce the yield of viable cardiomyocytes.

\section{Pre-plating of isolated cells}

12. Seed all the cells collected in horse serum on a sterile uncoated tissue culture dish. Place the dish containing the cells inside a sterile tissue culture incubator for $1 \mathrm{hr}$ maintained at $37^{\circ} \mathrm{C}$ and $5 \% \mathrm{CO}_{2}$, to allow the non-cardiomyocyte cells to attach to the plate. This step will help in enriching for the cardiomyocytes.

The cell suspension can be seeded onto a 10-cm dish when either 3-4 rat hearts or 5-6 mouse hearts are used. Scale-up or scale-down the dishes depending on the number of hearts processed.

This step exploits the differential attachment properties of the cardiomyocyte and non-cardiomyocyte populations, to specifically enrich for the cardiomyocytes. Noncardiomyocyte cells such as fibroblasts rapidly attach to uncoated tissue culture polystyrene plates, whereas cardiomyocytes remain in the supernatant as they weakly attach without a suitable substrate coating on the plates.

Monitor incubation time carefully. Incubations of more than $1 \mathrm{hr}$ can lead to attachment of cardiomyocytes and result in lesser yield of cardiomyocytes.

13. After $1 \mathrm{hr}$, remove the dish from the incubator and collect the supernatant containing unadhered cells in a Falcon tube. Centrifuge for $5 \mathrm{~min}$ at $200 \times \mathrm{g}$, room temperature.

\section{Seeding the cardiomyocytes}

14. Discard the supernatant from step 13 and resuspend the cell pellet in DMEM medium (use $2 \mathrm{ml}$ per 4 rat hearts or 10-12 mouse hearts) supplemented with 10\% FBS and antimycotic antibiotic mix.

The antibiotics in the medium can degrade with time and repeated thawing. Prepare antibiotics-containing medium freshly each time before use.

15. Count the cells using a hemacytometer, dilute as required in fresh DMEM with $10 \%$ FBS and antibiotics, and seed the cells on a sterile tissue culture plate coated with a suitable attachment substrate (see Support Protocol for coating procedure).

Approximately $10^{6}$ cardiomyocytes are obtained per rat heart or four mice hearts when this procedure is followed. The number can vary based on the efficiency of isolation. For confluent density of cardiomyocytes, seed $0.25 \times 10^{6}, 0.5 \times 10^{6}$, or $1 \times 10^{6}$ cells per well of a 24, 12, or 6-well plate, respectively. Use 0.5, 1, or $2 \mathrm{ml}$ of medium per well of 24 , 12, or 6-well plate, respectively so that the cells are completely covered with medium. If the cells are seeded on top of specialized bio-material substrates of substantial thickness, additional medium may be required to completely cover the cells.

16. Place the cells in a tissue culture incubator maintained at $37^{\circ} \mathrm{C}$ and $5 \% \mathrm{CO}_{2}$. 
The cardiomyocytes usually take around $24 \mathrm{hr}$ to attach and start growing. Some unattached cells may be floating at the end of $24 \mathrm{hr}$, which are basically non-viable cardiomyocytes. They can be discarded by changing the medium at the end of $24 \mathrm{hr}$. The cells may appear sub-confluent at this stage, but the cardiomyocytes will typically grow in size and fill the plate in the next $24 \mathrm{hr}$. The cells can be used for experiments when the cardiomyocytes are completely attached and display spontaneous contractions, a sign of functional cardiomyocytes (see Understanding Results). The contractions, however, may not be prominent if the media is old. Replenish the cells with fresh medium every 24-36 hr to observe the contractions.

The cultured cardiomyocytes stay healthy up to 4 weeks, though the spontaneous contractions may become less conspicuous after a week.

17. Optional: Eliminate the dividing non-myocyte population by culturing the cardiomyocytes in DMEM medium supplemented with $0.1 \mathrm{mM}$ 5-Bromo-2'deoxyuridine (BrdU) for 2-3 days to deplete the dividing non-myocyte population. Change the BrdU containing medium every $24 \mathrm{hr}$.

This is an optional step and may be performed if there is any carryover of non-myocyte dividing cells such as fibroblasts. Alternatively, the cardiomyocytes can be maintained in serum-free media for 24-48 hr to arrest the growth of dividing non-myocyte cells.

\section{COATING OF TISSUE CULTURE PLATES WITH EXTRACELLULAR MATRIX SUBSTRATES FOR EFFICIENT CARDIOMYOCYTE ATTACHMENT}

The primary cardiomyocytes require an extracellular matrix (ECM) coating to adhere onto the surface of culture dishes. The substrates on which the cardiomyocytes are grown play an important part in enhancing cell attachment, growth, and differentiation (Pagliarosi, Picchio, Chimenti, Messina, \& Gaetani, 2020). ECM-based coating such as fibronectin provide cell-adhesive motifs, recognized by the integrins present on the surface of cardiomyocytes, to improve cell-matrix interactions and thus, aid in their attachment to the substrate (Ruoslahti, 1988; Terracio et al., 1991). Moreover, in the absence of an ECM-coating, any small number of non-cardiomyocyte cells such as cardiac fibroblasts or endothelial cells present along with the cardiomyocytes may attach, proliferate, and out-grow the cardiomyocytes, as these cell types can attach in the absence of ECM coatings (Jain, Hasan, Desingu, Sundaresan, \& Chatterjee, 2018). Therefore, the culture dishes need to be coated with the ECM proteins to facilitate the efficient attachment of all the isolated cardiomyocytes. The procedure for coating the dishes is described here.

\section{Materials}

Gelatin (Sigma, cat. no. G9391) or fibronectin (Sigma, cat. no. F2006) or any other suitable attachment substrate (see recipe)

Phosphate-buffered saline (PBS; see recipe); needed if using keratin for coating the plates

Glass coverslips (0.17-mm thickness and diameter according to the size of the well plate used)

Tissue culture well plates (typically 24-, 12-, or 6-well plates)

\section{Coating of tissue culture plates}

1. Prepare a sterile solution of $0.2 \%$ (w/v) of gelatin or $25 \mu \mathrm{g} / \mathrm{ml}$ of fibronectin.

Alternatively, keratin obtained from human hair using an in-house extraction method, as described in Jain et al. (2017), can be used for coating the plates.

2. If the cardiomyocytes are intended to be processed for confocal/fluorescence microscopy, place sterilized coverslips inside the wells of a 12- or 24 well plate. 
The entire procedure from this step should be carried out inside a sterile cell culture hood to avoid any contamination.

3. Add 100,200 , or $400 \mu l$ of the coating solution per well of 24,12 , or 6 -well plates, respectively.

4. Incubate the plate with the coating solution for 15-30 $\mathrm{min}$ at room temperature inside the cell culture hood.

If using keratin for coating the plates, incubate the plates with the solution for $2 \mathrm{hr}$ at room temperature.

5. Remove the solution from the plates and allow the plates to air dry inside the tissue culture hood for 30-45 min.

Remove the solution along the edges of the well, and do not scratch the coated surfaces with the tips of the pipette. Do not over-dry the plates after coating, as it can disrupt the structure of coating and hinder the attachment of cells.

If using keratin, wash the coating with $1 \times P B S$ twice to neutralize the basic NaOH diluent and then air dry them.

The coated plates can be sealed and stored in a clean place up to 1 month at $4^{\circ} \mathrm{C}$. Check for any contamination or cracks on the surface before use.

\section{REAGENTS AND SOLUTIONS}

\section{BrdU stock solution}

To prepare a $10 \mathrm{mM}$ stock solution of BrdU, dissolve $3 \mathrm{mg}$ of BrdU in $1 \mathrm{ml}$ sterile water. The stock solution can be divided into aliquots and stored up to 1 year in a $-20^{\circ} \mathrm{C}$ freezer. Avoid repeated freeze-thawing. Store the solution in the dark.

CAUTION: BrdU is a carcinogen. Wear gloves and avoid direct contact with skin.

\section{Digestion mixture (DM)}

To prepare the digestion mixture containing $0.2 \%$ trypsin and $0.4 \mathrm{mg} / \mathrm{ml}$ collagenase Type II, mix $8 \mathrm{ml}$ of a $0.25 \%$ Trypsin solution w/o phenol red (HIMEDIA, cat. no. TCL006) and $4 \mathrm{mg}$ of collagenase type II lyophilized (Gibco, cat. no. 17101-015). Add sterile $1 \times$ PBSG buffer (see recipe) to a final volume of $10 \mathrm{ml}$. Filter sterilize the solution using a $0.22-\mu \mathrm{m}$ filter [Whatman International Ltd. (Merck), WHA99132502]. For storage, divide into aliquots and store the solution up to 3 months in $\mathrm{a}-20^{\circ} \mathrm{C}$ freezer. Avoid repeated freeze-thawing. Though the concentration of enzymes indicated here works good under most conditions, some optimization may be needed, as there could be lot-to-lot variation in the activity of enzymes used to prepare the digestion mixture. Once the concentrations are standardized for a given lot, use to the same lot for all the experiments.

\section{DMEM medium supplemented with 10\% FBS and antibiotic-antimycotic mix}

Dissolve 13.4 g of high-glucose DMEM (Sigma, cat. no. D5648) in $900 \mathrm{ml}$ of distilled water and adjust the $\mathrm{pH}$ to 7.4 with $\mathrm{HCl}$. Filter the medium through a 0.22 $\mu \mathrm{m}$ filter. Supplement the medium with $100 \mathrm{ml}$ of sterile fetal bovine serum (FBS, Gibco, cat. no. $10270106 ; 10 \%$ final concentration) and $10 \mathrm{ml}$ of $100 \times$ antibioticantimycotic mix (Gibco, 15240112). Prepare fresh.

\section{Fibronectin solution}

To prepare a $25 \mu \mathrm{g} / \mathrm{ml}$ solution of fibronectin, add $0.5 \mathrm{~g}$ of lyophilized fibronectin (Sigma, cat.no. F2006) to $20 \mathrm{ml}$ of sterile distilled water and dissolve by incubating for $30-60 \mathrm{~min}$ at $37^{\circ} \mathrm{C}$. Do not vortex or use excessive mechanical agitation. The solution can be stored up to 1 week at $4^{\circ} \mathrm{C}$. For long-term storage, divide the solution 
into aliquots and store up to 6 months in a $-20^{\circ} \mathrm{C}$ freezer. Avoid repeated freezethawing of the solution.

\section{Gelatin solution}

To prepare a $0.2 \%$ (w/v) solution, dissolve $0.2 \mathrm{~g}$ of gelatin (Sigma, cat. no. G9391) in $100 \mathrm{ml}$ of lukewarm distilled water and autoclave the solution for $20 \mathrm{~min}$ at $121^{\circ} \mathrm{C}$ and $15 \mathrm{psi}$. The solution can be stored indefinitely at $4^{\circ} \mathrm{C}$, as long as sterility is maintained. Divide into aliquots and warm the solution to $37^{\circ} \mathrm{C}$ before each use.

\section{PBSG buffer, $1 \times$}

Prepare and autoclave PBS (see recipe) and then add $1 \mathrm{ml}$ of $1 \mathrm{M}$ sterile filtered Dglucose solution (in water) to $100 \mathrm{ml}$ of $1 \times$ PBS so that the final concentration of glucose is $0.01 \mathrm{M}$. Do not autoclave with glucose. Store up to a month at $4^{\circ} \mathrm{C}$.

\section{Phosphate-buffered saline (PBS), $1 \times$}

Dissolve $137 \mathrm{mM} \mathrm{NaCl}, 2.7 \mathrm{mM} \mathrm{KCl}, 10 \mathrm{mM} \mathrm{Na} 2 \mathrm{HPO}_{4}$, and $1.8 \mathrm{mM} \mathrm{KH}_{2} \mathrm{PO}_{4}$ in double-distilled water. Adjust the $\mathrm{pH}$ to 7.4 with hydrochloric acid. Autoclave PBS before use in cell culture. Store up to a month at $4^{\circ} \mathrm{C}$.

\section{COMMENTARY}

\section{Background Information}

Cultured cardiomyocytes represent an excellent model system to study various aspects of cardiomyocyte physiology, as they closely mimic many in vivo properties of cardiomyocytes (Louch et al., 2011). Neonatal murine cardiomyocyte cultures can be used for in vitro studies on bioenergetics (Tachibana et al., 2019), electrophysiology (Nuss \& Marban, 1994), myofibrillogenesis (Liu et al., 2013; White et al., 2018), cell death (Fu et al., 2004), and mechanisms of drug-induced cardiotoxicity (Meng et al., 2019; Yu et al., 2020), and can serve as a model for hypoxia (Long et al., 1997; Tanaka et al., 1994) and hypertrophy (Miyata \& Haneda, 1994; Ravi et al., 2018; Sarikhani et al., 2018). Other practical applications of neonatal murine cardiomyocytes are discussed below, in Understanding Results.

Though cultured cardiomyocytes cannot completely substitute in vivo models for studying cardiac physiology and pathology (see below), cultured cardiomyocytes do offer certain distinct advantages over in vivo models. For instance, cultures provide a homogeneous population of cells that allows for selective manipulation of cardiomyocytes without significant interference by non-myocyte cells, which can be challenging to achieve in in vivo models. In addition, cultured cardiomyocytes allow for genetic manipulation and drug screening experiments to be carried out with relative ease and in shorter times, which are complicated and time-consuming in in vivo models. Notably, many of these advantages are replicated even when using cardiomyocyte cell lines such as HL-1, AT-1 and H9c2, which are relatively easier to culture and maintain. However, since these cells are immortalized, they fail to recapitulate the physiology and the terminally differentiated nature of the cardiomyocytes (Peter, Bjerke, \& Leinwand, 2016). Therefore, cultured primary cardiomyocytes tend to be superior in vitro models compared to immortalized cardiomyocyte cell lines.

Methods to culture cardiomyocytes from animal sources date back to more than a century (Burrows, 1912), while the first successful culture from a mammalian animal was reported by Harary and Farley in the 1960s when they isolated and cultivated cardiomyocytes from neonatal rats (Harary \& Farley, 1960, 1963a, 1963b). Though cardiomyocytes have been cultured from many other mammals, like hamsters (Thuringer, Coulombe, Deroubaix, Coraboeuf, \& Mercadier, 1996), rabbits (Haddad et al., 1988), and felines (Clark, Rudnick, LaPres, Lesch, \& Decker, 1991), murine cultures have been preferred for studies on cardiovascular biology for several reasons. First, rat and mice models are easily available and do not require elaborate housing systems; thus, cutting down the cost, skill, and staff requirements. Second, these two murine models have been well-studied and characterized, with many biological pathways understood in detail, making them ideal for research (Zaragoza et al., 2011). In addition, the availability of a wide variety of tools and reagents to manipulate and study these animals makes them highly useful model systems. 
Several modifications of the original method described by Harary and Farley (Harary \& Farley, 1960, 1963a, 1963b) have been reported, though the general principle of most methods has remained essentially the same. The methods described in the literature differ primarily with respect to the enzymes used for digestion and the digestion conditions. It is important to choose an appropriate enzyme for the dissociation of cardiac tissues, as the extracellular matrix holding the cardiac cells contains a complex mixture of proteins that differ in their susceptibilities to proteases. While trypsin is commonly used for dissociation of the heart cells, digestion for longer times with trypsin causes irreversible damages to cells and reduces viability $(\mathrm{Li}, \mathrm{Tu}-$ miati, Weisel, \& Mickle, 1993; Masson-Pevet, Jongsma, \& De Bruijne, 1976). On the other hand, collagenase has been shown to reduce cell injury, and studies have noted that combining trypsin with collagenase can increase the yield of viable cardiomyocytes as compared to collagenase alone (Kruppenbacher, May, Eggers, \& Piper, 1993; Li et al., 1993; Masson-Pevet et al., 1976). We therefore employed here a combination of both trypsin and collagenase type II, which results in efficient digestion. In addition, the protocol uses short, repeated cycles of digestion, instead of a single long digestion step, which minimizes the stress to the cells (Mark \& Strasser, 1966) and enhances the yield of viable cardiomyocytes. Further, the mechanical agitation of cells by shaking enhances the digestion and reduces the overall time required for digestion. The shaking conditions were optimized to increase the yield while minimizing the stress on the cells. Overall, the optimized protocol described here ensures high yield of viable and functional cardiomyocytes in less time than other protocols.

While here we focused on the isolation and culture of neonatal murine cardiomyocytes, these methods have been described for both neonatal and adult rat/mouse pups, each with its own advantages and disadvantages. The culture of neonatal cardiomyocytes presents certain distinct advantages. Firstly, culturing neonatal cardiomyocytes is technically easier and requires lesser instrumentation and hence, reduces overall cost. Adult cardiomyocyte culture, on the other hand, requires sophisticated instrumentation such as the Langendorff apparatus (Tian et al., 2020). Second, compared to neonatal cardiomyocytes, adult cardiomyocytes are sensitive to reintroduction into a calcium-containing media post isolation, drastically decreasing the overall yield for culture (Piper, Probst, Schwartz, Hutter, \& Spieckermann, 1982). Third, to successfully obtain a long-term (lasting for weeks to months) culture of adult cardiomyocytes, a trade-off has to be made with the physiological morphology and contractile properties of cells. While certain culture methods do permit the maintenance of the physiological properties of adult cardiomyocytes, such cultures only tend to last a few days. Moreover, such myocytes are quiescent and tend to lack the spontaneous contractile ability, and, therefore, require rapid electrical pacing (Mitcheson, Hancox, \& Levi, 1998). Finally, a major limitation with adult cardiomyocyte cultures is the inability to use routine, non-viral transfection methods, and can only be efficiently and stably transfected with viral-based methods such as using adenovirus or lentivirus (Louch et al., 2011). In contrast, neonatal cardiomyocytes are relatively easier to transfect using non-viral methods such as lipofection (Louch et al., 2011). Despite these limitations, adult cardiomyocyte cultures do offer various advantages. Adult cardiomyocytes tend to be better model systems to carry out studies that better recapitulate the in vivo molecular mechanisms of the adult heart (Mitcheson et al., 1998). In culture, adult cardiomyocytes show rapid series of dedifferentiation, wherein the cells initially round-up and essentially lose most of their cardiac phenotypes. However, with time, these cells show features of redifferentiation, where they attach, establish functional cell-cell connections, and tend to regain their functional cardiac phenotypes in culture; thus, adapting to the 2D culture system and allowing for in vitro studies (Eppenberger, Hertig, \& Eppenberger-Eberhardt, 1994). Notably, this dedifferentiation-redifferentiation cycle exhibited by adult cardiomyocytes in culture is accompanied by several structural and molecular changes that mimic the pathological changes that occur in a variety of adult cardiomyopathies, thus, proving to be excellent model systems for studying the plasticity of adult cardiomyocytes under varied physiological and pathological stimuli (Eppenberger et al., 1994). Moreover, in vitro cultures of adult cardiomyocytes provide greater flexibility of culture maintenance timelines, and last longer than neonatal cultures, thus, allowing for long-time studies in culture conditions (Ehler, Moore-Morris, \& Lange, 2013; Mitcheson et al., 1998), albeit 
Table 1 Some Common Issues and Troubleshooting

\begin{tabular}{|c|c|c|}
\hline Problem & Possible reasons & Solution \\
\hline \multirow[t]{6}{*}{$\begin{array}{l}\text { 1. Low yield of } \\
\text { cardiomyocytes }\end{array}$} & $\begin{array}{l}\text { 1. Chunks of heart tissues used } \\
\text { for digestion are too big }\end{array}$ & $\begin{array}{l}\text { Using large pieces of tissue may result in } \\
\text { inefficient digestion. Mince the tissue into } \\
\text { small chunks of } \sim 1 \mathrm{~mm}^{3} \text { and then } \\
\text { perform digestion, for best results. }\end{array}$ \\
\hline & $\begin{array}{l}\text { 2. Insufficient digestion mixture } \\
\text { added }\end{array}$ & $\begin{array}{l}\text { Ensure that enough DM is added }(75 \mu \mathrm{l} \\
\text { per rat heart or four mouse hearts) }\end{array}$ \\
\hline & $\begin{array}{l}\text { 3. Shaking and temperature } \\
\text { conditions not maintained } \\
\text { properly }\end{array}$ & $\begin{array}{l}\text { Ensure the incubator shaker is set at } 250 \\
\mathrm{rpm} \text { and } 37^{\circ} \mathrm{C} \text { during digestion. Confirm } \\
\text { the temperature with a thermometer, if } \\
\text { needed. }\end{array}$ \\
\hline & $\begin{array}{l}\text { 4. Inefficient digestion due to } \\
\text { poor quality of digestion } \\
\text { reagents. }\end{array}$ & $\begin{array}{l}\text { Ensure the digestion enzymes are fresh } \\
\text { and stored properly to avoid any } \\
\text { reduction in their activity with time. }\end{array}$ \\
\hline & 5. Insufficient cycles of digestion & $\begin{array}{l}\text { Perform 9-10 rounds of digestion or until } \\
\text { the tissue is digested, whichever happens } \\
\text { first. Fewer cycles of digestion will result } \\
\text { in incomplete digestion of tissue. }\end{array}$ \\
\hline & 6. Excess pre-plating time & $\begin{array}{l}\text { Avoid pre-plating for more than } 1 \mathrm{hr} \text {, as } \\
\text { some cardiomyocytes may also attach to } \\
\text { the plate on longer pre-plating } \\
\text { incubations. }\end{array}$ \\
\hline \multirow[t]{4}{*}{ 2. Low viability } & 1. Excessive digestion & $\begin{array}{l}\text { Avoid more than } 10 \text { rounds of digestions } \\
\text { or performing the digestion for more than } \\
5 \text { min in each round. }\end{array}$ \\
\hline & 2. Excessive mechanical stress & $\begin{array}{l}\text { Avoid grinding or crushing the tissue. Do } \\
\text { not use excessive force while mincing the } \\
\text { tissues, and do not cut them into very } \\
\text { small pieces. Avoid harsh/long vortexing } \\
\text { in between digestion steps. Maintain the } \\
\text { shaking speed at not more than } 250 \mathrm{rpm} \text {. }\end{array}$ \\
\hline & $\begin{array}{l}\text { 3. Appropriate temperature not } \\
\text { maintained during harvesting } \\
\text { and digestion steps }\end{array}$ & $\begin{array}{l}\text { Place the heart on ice-cold PBSG buffer } \\
\text { immediately after excision. After each } \\
\text { digestion, maintain the cells collected in } \\
\text { horse serum in the cell culture incubator } \\
\text { at } 37^{\circ} \mathrm{C} \text {. }\end{array}$ \\
\hline & 4. Dishes not coated properly & $\begin{array}{l}\text { Ensure the tissue culture plates for } \\
\text { seeding the cardiomyocytes are coated } \\
\text { with proper adhesion substrates. }\end{array}$ \\
\hline $\begin{array}{l}\text { 3. Bacterial/fungal } \\
\text { contamination }\end{array}$ & $\begin{array}{l}\text { 1. Non-sterile dissection } \\
\text { tools/reagents/tissue culture } \\
\text { ware }\end{array}$ & $\begin{array}{l}\text { Sterilize all dissection tools thoroughly } \\
\text { and clean the pups gently but thoroughly. } \\
\text { Use a separate pair of scissors for } \\
\text { decapitation and dissection. Autoclave } \\
\text { the PBSG buffer and filter-sterilize the } \\
\text { digestion mixture, horse serum, and the } \\
\text { substrate used for coating places. Always } \\
\text { use tissue culture-grade reagents. Use } \\
\text { sterile Falcon tubes for collecting the } \\
\text { cells and use tissue culture-grade sterile } \\
\text { tissue culture polystyrene plates. }\end{array}$ \\
\hline
\end{tabular}

(Continued) 
Table 1 Some Common Issues and Troubleshooting, continued

\begin{tabular}{|c|c|c|}
\hline Problem & Possible reasons & Solution \\
\hline & $\begin{array}{l}\text { 2. Contaminated incubator/tissue } \\
\text { culture hood }\end{array}$ & $\begin{array}{l}\text { Decontaminate the incubator by heat } \\
\text { sterilization, if the option is available. } \\
\text { Fumigate or UV sterilize the tissue } \\
\text { culture facility on a regular basis. Check } \\
\text { other plates in the incubator for } \\
\text { contamination. If any of them are } \\
\text { contaminated, discard the plates and } \\
\text { sterilize the incubator. } \\
\text { UV sterilize the tissue culture hood for at } \\
\text { least } 30 \text { min before use. Sterilize the } \\
\text { surface and the media/reagent bottles } \\
\text { placed inside the hood with } 70 \% \text { ethanol } \\
\text { before use. }\end{array}$ \\
\hline & 3. Antibiotics not effective & $\begin{array}{l}\text { Avoid repeated freeze-thawing of media } \\
\text { with antibiotics. Add antibiotics to } \\
\text { antibiotic-free medium before each use. }\end{array}$ \\
\hline \multirow{3}{*}{$\begin{array}{l}\text { 4. Contamination by } \\
\text { non-cardiomyocyte } \\
\text { population }\end{array}$} & 1. Insufficient pre-plating & $\begin{array}{l}\text { Do not reduce the pre-plating time to less } \\
\text { than } 1 \mathrm{hr} \text {. }\end{array}$ \\
\hline & $\begin{array}{l}\text { 2. Non-cardiac tissues not } \\
\text { removed completely while } \\
\text { harvesting the heart }\end{array}$ & $\begin{array}{l}\text { Remove any additional tissues such as } \\
\text { from the lung, diaphragm, or connective } \\
\text { tissue sticking to the heart. Remove the } \\
\text { major blood vessels such as the aorta. }\end{array}$ \\
\hline & $\begin{array}{l}\text { 3. Contamination by } \\
\text { proliferating cells like fibroblasts }\end{array}$ & $\begin{array}{l}\text { Maintain the cardiomyocytes in } \\
\text { serum-free media for } 24-36 \mathrm{hr} \text { after } \\
\text { seeding. While allowing the growth of the } \\
\text { non-dividing cardiomyocytes, serum-free } \\
\text { media prevents the proliferation of other } \\
\text { dividing non-myocyte population. } \\
\text { Alternatively, maintain the } \\
\text { cardiomyocytes in culture media } \\
\text { containing } 0.1 \mathrm{mM} \\
\text { 5-Bromo-2'-deoxyuridine (BrdU) for } 2-3 \\
\text { days to deplete the dividing non-myocyte } \\
\text { population. Change the BrdU containing } \\
\text { medium every } 24 \mathrm{hr} \text {. }\end{array}$ \\
\hline
\end{tabular}

with certain modifications in the procedure as mentioned above.

While cultured cardiomyocytes offer several advantages, it is also important to be aware of their limitations. Myocytes cultured in vitro tend to adapt to the regularly fluctuating culture conditions and thus, cannot be considered to sustain a steady physiological state. Moreover, cell culture is a 2D environment, which drastically differs from the in vivo 3D environment. Thus, the adaptation of cells to the $2 \mathrm{D}$ culture conditions involves various physical and molecular changes, thus, changing many of the properties associated with their in vivo function (Mitcheson et al., 1998). The use of patterned biomaterial substrates that guide cardiomyocyte growth similar to in vivo environments have been explored, which circumvents some of these issues (Jain et al., 2018). However, these models are still technically 2D cultures and, therefore, do not completely represent the in vivo environment. Therefore, studies in cultured myocytes can be considered as a good starting point and can be used to supporting studies done in vivo model systems (Mitcheson et al., 1998).

\section{Critical Parameters and Troubleshooting}

Key considerations and tips to avoid potential issues have been mentioned alongside each of the steps, wherever possible. Some 
A

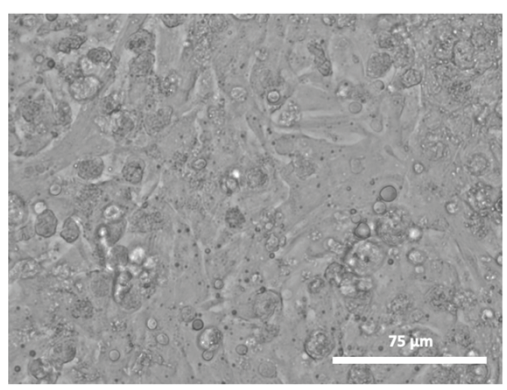

D
B

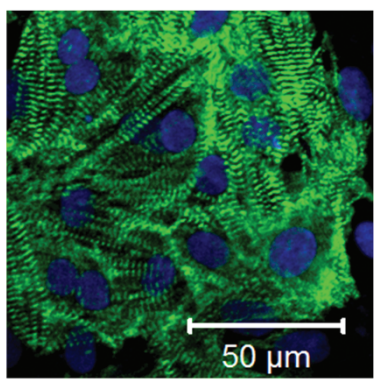

Sarcomeric $\alpha$-Actinin DAPI
C

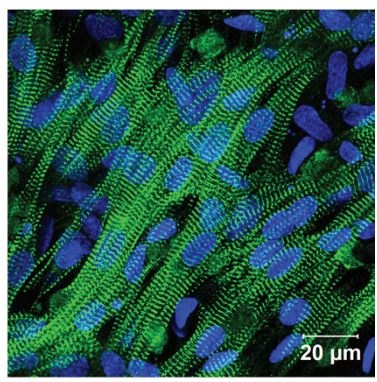

Myomesin Hoechst

E

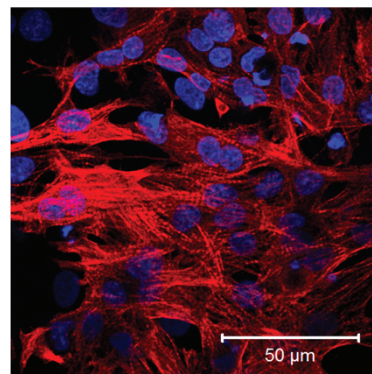

Troponin I DAPI

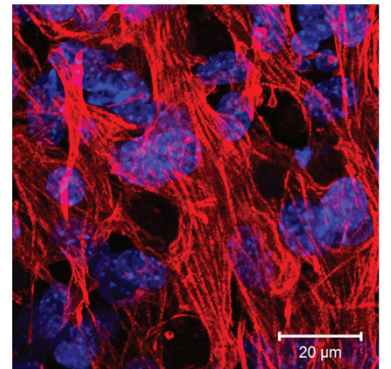

cTNT Hoechst

Figure 2 (A) Bright-field image of neonatal rat cardiomyocytes cultured on gelatin coated dishes. Scale bar $=75 \mu \mathrm{m}$. (B) Neonatal primary rat cardiomyocytes cultured on fibronectin and immuno-stained with sarcomeric $\alpha$-Actinin (green). Nuclei were stained with DAPI (blue). Scale bar $=50 \mu \mathrm{m}$. (C) Neonatal rat cardiomyocytes cultured on gelatin and immuno-stained with myomesin (green). Nuclei were stained with Hoeschst 33342 (blue). Scale bar $=20 \mu \mathrm{m}$. (D) Neonatal rat cardiomyocytes cultured on gelatin and immuno-stained with troponin I (green); nuclei were stained with DAPI (blue). Scale bar $=50 \mu \mathrm{m}$. (E) Neonatal mice cardiomyocytes cultured on gelatin and immuno-stained with cardiac troponin T (cTnT, red), and the nuclei were stained with Hoechst 33342 (blue). Scale bar $=20 \mu \mathrm{m}$. The antibodies used are sarcomeric $\alpha$-Actinin (Sigma, cat. no. A7811), myomesin (DSHB, mMaC myomesin B4), cTnT (Abcam, ab10214), and troponin I (Cloud clone, PAA478Ra01).

additional critical points and troubleshooting advise are outlined in Table 1.

\section{Understanding Results}

Here, we describe what users should expect to observe if they follow the protocols described above. In addition, we describe some uses for the cultured cardiomyocytes and results that can be obtained when employing them to study various aspects of cardiomyocyte biology.

\section{Visualization and characterization of cultured cardiomyocytes}

Cultured cardiomyocytes appear rounded in the initial stages during the first $24 \mathrm{hr}$ after culture. The cardiomyocytes then flatten and attach firmly to the substrate, forming a confluent monolayer of elongated cylindrical cells (Fig. 2A). Non-viable cells do not attach and remain rounded, which can be washed off while changing the medium. The cardiomyocytes begin to display spontaneous contractions $24-48 \mathrm{hr}$ post culture, which indicates healthy and functional cardiomyocytes (see Video 1). The rapid calcium currents in the cardiomyocytes responsible for their contractile property can be observed by live-cell imaging using calcium-sensitive fluorescent indicators such as Fluo-4 (Video 2). The cultured cardiomyocytes can also be immunostained with cardiomyocyte-specific markers such as sarcomeric $\alpha$-actinin, myomesin, cardiac troponin $\mathrm{T}$, or cardiac troponin $\mathrm{I}$, and visualized by confocal microscopy (Fig. 2BE). Detailed procedures for these assays can be found in (Jain et al., 2017). These assays can also be used to test how specific toxicants or drugs affect these parameters on cultured cardiomyocytes obtained as described in Basic Protocol.
Ravi et al. 


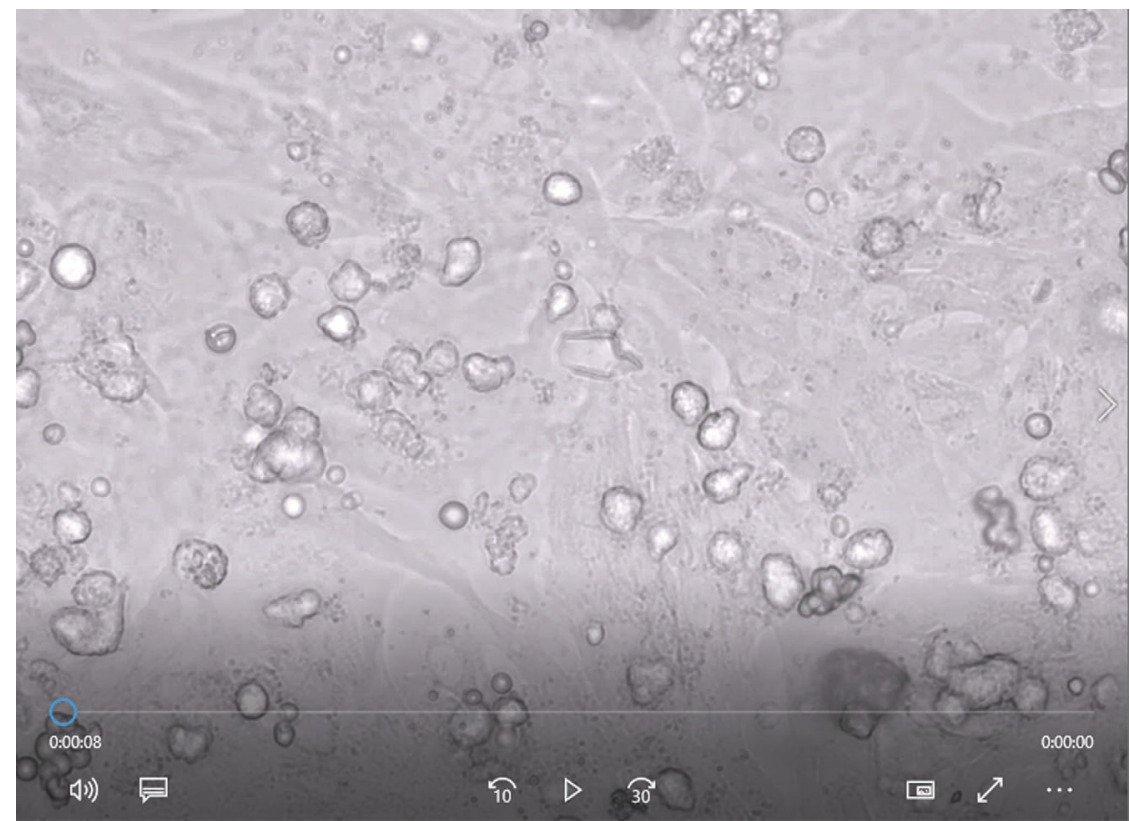

Video 1 Bright field videos of neonatal rat cardiomyocytes at $40 \times$ magnification $24 \mathrm{~h}$ post culture displaying synchronous contractions.

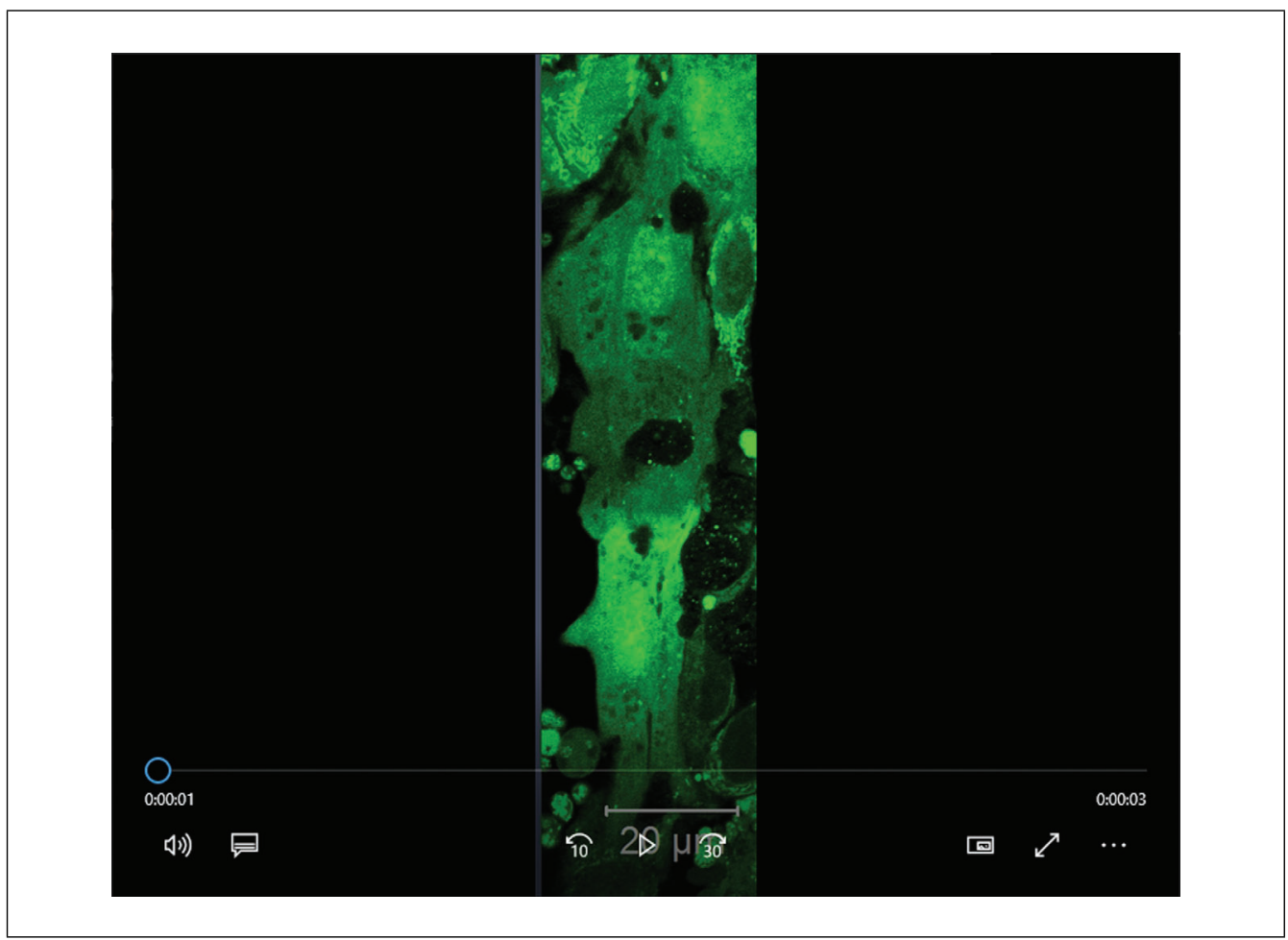

Video 2 Live imaging of calcium transients in neonatal rat cardiomyocytes using the calciumsensitive fluorescent indicators Fluo-4 (Thermo, F10489) at $63 \times$ magnification and 1.1× zoom.

\section{Evaluating cardiac hypertrophy}

Cultured primary cardiomyocytes represent a useful in vitro model system to study the phenomenon of cardiomyocyte hypertrophy (Miyata \& Haneda, 1994; Ravi et al., 2018; Sarikhani et al., 2018). The system can be used to evaluate the effect of various extracel- lular/intracellular signals as well as the effect of specific genes on the development of hypertrophy. Cardiomyocytes obtained and cultured following the Basic Protocol can be induced to develop hypertrophy by treatment with hypertrophic agents such as phenylephrine or angiotensin II. Alternatively, the role of 
A

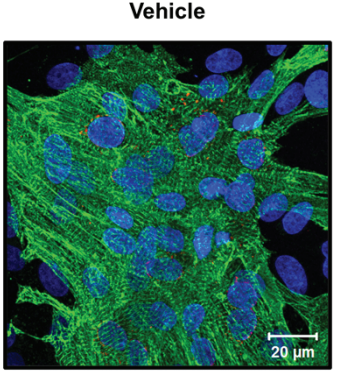

Sarcomeric a-Actinin DAPI ANP

B

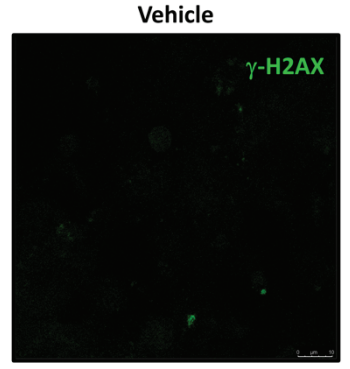

PE
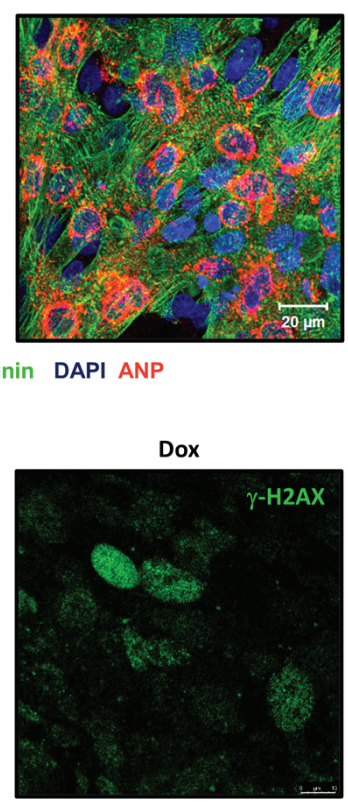

C

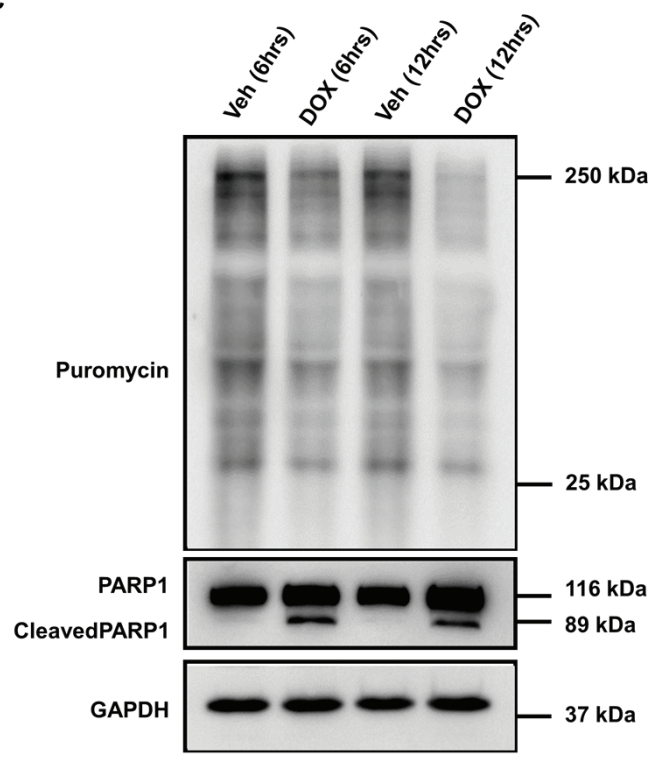

Figure 3 (A) Neonatal rat cardiomyocytes treated for $48 \mathrm{hr}$ with vehicle or $20 \mu \mathrm{M}$ phenylephrine (PE) and stained with ANP (red), used as a marker for the induction of hypertrophy. The cardiomyocytes were marked with sarcomeric $\alpha$-Actinin (green), and nuclei were stained with DAPI (blue). Scale bar $=20 \mu \mathrm{m}$. The antibodies used were ANP (Abcam ab14348) and sarcomeric $\alpha$-Actinin (Sigma, A7811). (B) Neonatal rat cardiomyocytes were treated for $24 \mathrm{hr}$ with vehicle or $1 \mu \mathrm{M}$ doxorubicin (DOX) and stained with $\gamma \mathrm{H} 2 \mathrm{AX}$ (green), a marker of DNA damage. The nuclei were stained with Hoechst 33342 (blue). Scale bar $=10 \mu \mathrm{m}$. The antibody used here is $\gamma \mathrm{H} 2 \mathrm{AX}$ (Cell Signaling, \#80312). (C) Western blot SUnSET analysis of protein synthesis in neonatal rat primary cardiomyocytes treated with vehicle or $1 \mu \mathrm{M}$ doxorubicin (DOX) for $6 \mathrm{hr}$ and $12 \mathrm{hr}$. PARP1 cleavage was used to confirm the action of doxorubicin, and GAPDH was used as a loading control. The antibodies used were puromycin (DSHB, PMY2A4), PARP (Cell Signaling, cat. no. 9532) and GAPDH (Sigma, cat. no. G9545).

different genes in the induction of hypertrophy can be studied by specifically depleting or overexpressing the proteins of interest in the cardiomyocytes and assessing the development of hypertrophy. The development of hypertrophy in cardiomyocytes can be assessed using several parameters such as increase in cell size, re-expression of fetal genes, and enhanced protein synthesis (Frey, Katus, Olson, \& Hill, 2004). Among the markers of pathological cardiac hypertrophy is the expression of fetal-gene protein ANP (atrial natriuretic peptide) by cardiomyocytes (Booz, 2005). Figure 3A shows the increased expression of ANP in the perinuclear region of phenylephrine-treated cardiomyocytes, which is characteristic of the induction of cardiac hypertrophy. Additional methods and examples for evaluating the development of hypertrophy in cardiomyocytes can be found in our previous publications (Jain et al., 2017; Ravi et al., 2018). The cultured cardiomyocytes can also be used for large-scale screening of drugs or gene candidates for the treatment of cardiac hypertrophy.

\section{Evaluating drug-induced cardiotoxicity}

Primary cardiomyocytes obtained following the Basic Protocol can be used to evaluate and to study the mechanisms underlying drug-induced cardiotoxicity. Specifically, cardiomyocytes are prone to damage and dysfunction by the action of anthracycline class of chemotherapeutic drugs like doxorubicin (Wenningmann, Knapp, Ande, Vaidya, \& AitOudhia, 2019). Primary cardiomyocytes have been extensively used to study the mechanisms of doxorubicin-induced cardiotoxicity (Altieri et al., 2016; Kobayashi et al., 2010; Ueno et al., 2006). Doxorubicin induces double-stranded breaks in cardiomyocytes, which can be visualized by immunostaining for the $\gamma-\mathrm{H} 2 \mathrm{AX}$, as shown in Figure 3B. In addition, we have evaluated changes in protein synthesis following doxorubicin treatment of cardiomyocytes using the non-radioactive SUnSET assay (see Ravi, Jain, Mishra, \& Sundaresan, 2020) for a detailed protocol of the SUnSET assay). Treatment with $1 \mu \mathrm{M}$ doxorubicin markedly reduced protein synthesis in cardiomyocytes in a time-dependent manner
Ravi et al.

15 of 19 
Table 2 Time Considerations

Procedure Time (hr:min) Additional notes

\section{Basic Protocol}

Ethanol decontamination of pups

Animal euthanasia

$00: 15$

Harvesting hearts from

animals

Digestion of heart tissue and

$01: 30$

collection of cells

Pre-plating of isolated cells

$01: 30$

Counting and seeding

cardiomyocytes

Total

\section{Support Protocol}

Addition of coating solution

and incubation

(gelatin/fibronectin)

Removal of solution and air-drying
The time indicated is for 5-7 animals. Scale-up or scale-down accordingly
The indicated times may vary according to the number of animals used and the user's expertise.

For keratin, the coating solution should be incubated for $2 \mathrm{hr}$

$00: 30$
The coating can be completed parallelly during the $1 \mathrm{hr}$ pre-plating step to save time and also led to cleavage of PARP1, which is indicative of the induction of apoptotic cell death (Fig. 3C). The cultured cardiomyocytes can be similarly used for evaluating the toxicity profiles of various drugs and to study cellular and sub-cellular changes resulting from their exposure to these chemicals.

\section{Time Considerations}

The typical time required to complete the different stages involved in the protocols described in this article is presented in Table 2.

\section{Acknowledgments}

This work is supported by funding from the Government of India [EMR/2014/ 000065] - Department of Science and Technology Extra Mural Research Funding, [BRB/10/1294/2014 and MED/30/1454/ 2014] - Department of Biotechnology Extramural Research Grants, [37(1646)/15/EMRII]-Council for Scientific and Industrial Research extramural research support, and the Department of Biotechnology-Indian Institute of Science partnership program for advanced research.

\section{Author Contributions}

Venkatraman Ravi: data curation, formal analysis, investigation, methodology, resources, writing-original draft, writingreview and editing, Aditi Jain: data curation, formal analysis, investigation, methodology, resources, writing-original draft, Arushi Taneja: data curation, formal analysis, investigation, methodology, writing-original draft, Kaushik Chatterjee: funding acquisition, project administration, resources, supervision, writing-review and editing, N. Ravi Sundaresan: funding acquisition, project administration, resources, supervision, writing-review and editing.

\section{Conflict of Interest}

The authors declare no conflict of interest.

\section{Data Availability Statement}

The data that support the findings of this study are available on request from the corresponding author.

\section{Literature Cited}

Altieri, P., Barisione, C., Lazzarini, E., Garuti, A., Bezante, G. P., Canepa, M. ... Ameri, P. (2016). Testosterone antagonizes doxorubicin-induced senescence of cardiomyocytes. Journal of the American Heart Association, 5(1), e002383. doi: 10.1161/JAHA.115.002383.

Booz, G. W. (2005). Putting the brakes on cardiac hypertrophy: Exploiting the NO-cGMP counterregulatory system. Hypertension, 45(3), 
341-346. doi: 10.1161/01.HYP.0000156878. 17006.02.

Burrows, M. T. (1912). Rhythmical activity of isolated heart muscle cells in vitro. Science, 36(916), 90-92. doi: 10.1126/science.36.916. 90.

Clark, W. A., Rudnick, S. J., LaPres, J. J., Lesch, M., \& Decker, R. S. (1991). Hypertrophy of isolated adult feline heart cells following betaadrenergic-induced beating. American Journal of Physiology, 261(3 Pt 1), C530-542. doi: 10. 1152/ajpcell.1991.261.3.C530.

Donovan, J., \& Brown, P. (2005). Euthanasia. Current Protocols in Neuroscience, APPENDIX 4, APPENDIX 4H. doi: 10.1002/0471142301. nsa04hs33.

Ehler, E., Moore-Morris, T., \& Lange, S. (2013). Isolation and culture of neonatal mouse cardiomyocytes. Journal of Visualized Experiments, 6, (79):50154. doi: 10.3791/50154.

Eppenberger, H. M., Hertig, C., \& EppenbergerEberhardt, M. (1994). Adult rat cardiomyocytes in culture A model system to study the plasticity of the differentiated cardiac phenotype at the molecular and cellular levels. Trends in Cardiovascular Medicine, 4(4), 187-193. doi: 10. 1016/1050-1738(94)90056-6.

Frey, N., Katus, H. A., Olson, E. N., \& Hill, J. A. (2004). Hypertrophy of the heart: A new therapeutic target? Circulation, 109(13), 1580-1589. doi: 10.1161/01.CIR.0000120390.68287BB

Fu, Y. C., Chi, C. S., Yin, S. C., Hwang, B., Chiu, Y. T., \& Hsu, S. L. (2004). Norepinephrine induces apoptosis in neonatal rat cardiomyocytes through a reactive oxygen species-TNF alpha-caspase signaling pathway. Cardiovascular Research, 62(3), 558-567. doi: 10.1016/j. cardiores.2004.01.039.

Haddad, J., Decker, M. L., Hsieh, L. C., Lesch, M., Samarel, A. M., \& Decker, R. S. (1988). Attachment and maintenance of adult rabbit cardiac myocytes in primary cell culture. American Journal of Physiology, 255(1 Pt 1), C19-27. doi: 10.1152/ajpcell.1988.255.1.C19.

Harary, I., \& Farley, B. (1960). In vitro studies of single isolated beating heart cells. Science, 131(3414), 1674-1675. doi: 10.1126/science. 131.3414.1674.

Harary, I., \& Farley, B. (1963a). In vitro studies on single beating rat heart cells. I. Growth and organization. Experimental Cell Research, 29, 451465. doi: 10.1016/S0014-4827(63)80008-7.

Harary, I., \& Farley, B. (1963b). In vitro studies on single beating rat heart cells. II. Intercellular communication. Experimental Cell Research, 29, 466-474. doi: 10.1016/S0014-4827(63) 80009-9.

Jacot, J. G., McCulloch, A. D., \& Omens, J. H. (2008). Substrate stiffness affects the functional maturation of neonatal rat ventricular myocytes. Biophysical Journal, 95(7), 3479-3487. doi: 10. 1529/biophysj.107.124545.

Jain, A., Hasan, J., Desingu, P. A., Sundaresan, N. R., \& Chatterjee, K. (2018). Engineering an in vitro organotypic model for studying cardiac hypertrophy. Colloids Surf B Biointerfaces, 165, 355-362. doi: 10.1016/j.colsurfb.2018.02. 036.

Jain, A., Ravi, V., Muhamed, J., Chatterjee, K., \& Sundaresan, N. R. (2017). A simplified protocol for culture of murine neonatal cardiomyocytes on nanoscale keratin coated surfaces. International Journal of Cardiology, 232, 160-170. doi: 10.1016/j.ijcard.2017.01. 036.

Jentzsch, C., Leierseder, S., Loyer, X., Flohrschutz, I., Sassi, Y., Hartmann, D. ... Engelhardt, S. (2012). A phenotypic screen to identify hypertrophy-modulating microRNAs in primary cardiomyocytes. Journal of Molecular and Cellular Cardiology, 52(1), 13-20. doi: 10. 1016/j.yjmcc.2011.07.010.

Kobayashi, S., Volden, P., Timm, D., Mao, K., Xu, X., \& Liang, Q. (2010). Transcription factor GATA4 inhibits doxorubicin-induced autophagy and cardiomyocyte death. Journal of Biological Chemistry, 285(1), 793-804. doi: 10. 1074/jbc.M109.070037.

Kruppenbacher, J. P., May, T., Eggers, H. J., \& Piper, H. M. (1993). Cardiomyocytes of adult mice in long-term culture. Naturwissenschaften, 80(3), 132-134. doi: 10.1007/BF01131017.

Li, R. K., Tumiati, L. C., Weisel, R. D., \& Mickle, D. A. G. (1993). Isolation of cardiomyocytes from human myocardium for primary cell culturing. Journal of Tissue Culture Methods, 15(3), 147-154. doi: 10.1007/BF02388268.

Liu, H., Shao, Y., Qin, W., Runyan, R. B., Xu, M., Ma, Z. ... Gao, B. Z. (2013). Myosin filament assembly onto myofibrils in live neonatal cardiomyocytes observed by TPEF-SHG microscopy. Cardiovascular Research, 97(2), 262-270. doi: 10.1093/cvr/cvs328.

Long, X., Boluyt, M. O., Hipolito, M. L., Lundberg, M. S., Zheng, J. S., O’Neill, L. ... Crow, M. T. (1997). p53 and the hypoxia-induced apoptosis of cultured neonatal rat cardiac myocytes. Journal of Clinical Investigation, 99(11), 26352643. doi: 10.1172/JCI119452.

Louch, W. E., Sheehan, K. A., \& Wolska, B. M. (2011). Methods in cardiomyocyte isolation, culture, and gene transfer. Journal of Molecular and Cellular Cardiology, 51(3), 288-298. doi: 10.1016/j.yjmcc.2011.06.012.

Mark, G. E., \& Strasser, F. F. (1966). Pacemaker activity and mitosis in cultures of newborn rat heart ventricle cells. Experimental Cell Research, 44(2), 217-233. doi: 10.1016/ 0014-4827(66)90427-7.

Masson-Pevet, M., Jongsma, H. J., \& De Bruijne, J. (1976). Collagenase- and trypsin-dissociated heart cells: A comparative ultrastructural study. Journal of Molecular and Cellular Cardiology, 8(10), 747-757. doi: 10.1016/0022-2828(76) 90082-1.

Meng, L., Lin, H., Zhang, J., Lin, N., Sun, Z., Gao, F. ... Guo, H. (2019). Doxorubicin induces cardiomyocyte pyroptosis via the TINCR-mediated posttranscriptional stabilization of NLR family
Ravi et al. 
pyrin domain containing 3. Journal of Molecular and Cellular Cardiology, 136, 15-26. doi: 10.1016/j.yjmcc.2019.08.009.

Mitcheson, J. S., Hancox, J. C., \& Levi, A. J. (1998). Cultured adult cardiac myocytes: Future applications, culture methods, morphological and electrophysiological properties. Cardiovascular Research, 39(2), 280-300. doi: 10. 1016/s0008-6363(98)00128-x.

Miyata, S., \& Haneda, T. (1994). Hypertrophic growth of cultured neonatal rat heart cells mediated by type 1 angiotensin II receptor. American Journal of Physiology, 266(6 Pt 2), H24432451. doi: 10.1152/ajpheart.1994.266.6. $\mathrm{H} 2443$.

Nuss, H. B., \& Marban, E. (1994). Electrophysiological properties of neonatal mouse cardiac myocytes in primary culture. Journal of Physiology, 479(Pt 2), 265-279. doi: 10.1113/jphysiol. 1994.sp020294.

Pagliarosi, O., Picchio, V., Chimenti, I., Messina, E., \& Gaetani, R. (2020). Building an artificial cardiac microenvironment: A focus on the extracellular matrix. Frontiers in Cell and Developmental Biology, 8, 559032. doi: 10.3389/fcell. 2020.559032.

Peter, A. K., Bjerke, M. A., \& Leinwand, L. A. (2016). Biology of the cardiac myocyte in heart disease. Molecular Biology of the Cell, 27(14), 2149-2160. doi: 10.1091/mbc.E16-01-0038.

Piper, H. M., Probst, I., Schwartz, P., Hutter, F. J., \& Spieckermann, P. G. (1982). Culturing of calcium stable adult cardiac myocytes. Journal of Molecular and Cellular Cardiology, 14(7), 397-412. doi: 10.1016/0022-2828(82)90171-7.

Ravi, V., Jain, A., Ahamed, F., Fathma, N., Desingu, P. A., \& Sundaresan, N. R. (2018). Systematic evaluation of the adaptability of the nonradioactive SUnSET assay to measure cardiac protein synthesis. Science Report, 8(1), 4587. doi: 10.1038/s41598-018-22903-8.

Ravi, V., Jain, A., Mishra, S., \& Sundaresan, N. R. (2020). Measuring protein synthesis in cultured cells and mouse tissues using the nonradioactive SUnSET Assay. Current Protocols in Neuroscience Molecular Biology, 133(1), e127. doi: 10.1002/cpmb.127.

Reid, B. G., Stratton, M. S., Bowers, S., Cavasin, M. A., Demos-Davies, K. M., Susano, I., \& McKinsey, T. A. (2016). Discovery of novel small molecule inhibitors of cardiac hypertrophy using high throughput, high content imaging. Journal of Molecular and Cellular Cardiology, 97, 106-113. doi: 10.1016/j.yjmcc.2016. 04.015.

Ruoslahti, E. (1988). Fibronectin and its receptors. Annual Review of Biochemistry, 57, 375-413. doi: 10.1146/annurev.bi.57.070188.002111.

Sarikhani, M., Maity, S., Mishra, S., Jain, A., Tamta, A. K., Ravi, V. ... Sundaresan, N. R. (2018). SIRT2 deacetylase represses NFAT transcription factor to maintain cardiac homeostasis. Journal of Biological Chemistry, 293(14), 5281-5294. doi: 10.1074/jbc.RA117.000915.
Shomer, N. H., Allen-Worthington, K. H., Hickman, D. L., Jonnalagadda, M., Newsome, J. T., Slate, A. R. ... Wilkinson, M. (2020). Review of Rodent Euthanasia Methods. Journal of the American Association for Laboratory Animal Science, 59(3), 242-253. doi: 10.30802/ AALAS-JAALAS-19-000084.

Tachibana, S., Chen, C., Zhang, O. R., Schurr, S. V., Hill, C., Li, R. ... Cho, Y. (2019). Analyzing oxygen consumption rate in primary cultured mouse neonatal cardiomyocytes using an extracellular flux analyzer. Journal of Visualized Experiments, (144), 10.3791/59052. doi: $10.3791 / 59052$

Tanaka, M., Ito, H., Adachi, S., Akimoto, H., Nishikawa, T., Kasajima, T. ... Hiroe, M. (1994). Hypoxia induces apoptosis with enhanced expression of Fas antigen messenger RNA in cultured neonatal rat cardiomyocytes. Circulation Research, 75(3), 426-433. doi: 10. 1161/01.RES.75.3.426.

Terracio, L., Rubin, K., Gullberg, D., Balog, E., Carver, W., Jyring, R., \& Borg, T. K. (1991). Expression of collagen binding integrins during cardiac development and hypertrophy. Circulation Research, 68(3), 734-744. doi: 10.1161/01. res.68.3.734.

Thuringer, D., Coulombe, A., Deroubaix, E., Coraboeuf, E., \& Mercadier, J. J. (1996). Depressed transient outward current density in ventricular myocytes from cardiomyopathic Syrian hamsters of different ages. Journal of Molecular and Cellular Cardiology, 28(2), 387-401. doi: 10.1006/jmcc.1996.0036.

Tian, X., Gao, M., Li, A., Liu, B., Jiang, W., Qin, Y., \& Gong, G. (2020). Protocol for isolation of viable adult rat cardiomyocytes with high yield. STAR Protocols, 1(2), 100045. doi: 10.1016/j. xpro.2020.100045.

Ueno, M., Kakinuma, Y., Yuhki, K., Murakoshi, N., Iemitsu, M., Miyauchi, T., \& Yamaguchi, I. (2006). Doxorubicin induces apoptosis by activation of caspase- 3 in cultured cardiomyocytes in vitro and rat cardiac ventricles in vivo. Journal of Pharmacological Sciences, 101(2), 151158. doi: 10.1254/jphs.fp0050980.

Volkova, M., \& Russell, R. 3rd. (2011). Anthracycline cardiotoxicity: Prevalence, pathogenesis and treatment. Current Cardiology Reviews, 7(4), 214-220. doi: 10.2174/157340311 799960645.

Wells, S. P., Waddell, H. M., Sim, C. B., Lim, S. Y., Bernasochi, G. B., Pavlovic, D. ... Bell, J. R. (2019). Cardiomyocyte functional screening: Interrogating comparative electrophysiology of high-throughput model cell systems. American Journal of Physiology-Cell Physiology, 317(6), C1256-C1267. doi: 10.1152/ ajpcell.00306.2019.

Wenningmann, N., Knapp, M., Ande, A., Vaidya, T. R., \& Ait-Oudhia, S. (2019). Insights into doxorubicin-induced cardiotoxicity: molecular mechanisms, preventive strategies, and early monitoring. Molecular Pharmacology, 96(2), 219-232. doi: 10.1124/mol.119.115725. 
White, J., Wang, J., Fan, Y., Dube, D. K., Sanger, J. W., \& Sanger, J. M. (2018). Myofibril assembly in cultured mouse neonatal cardiomyocytes. Anatomical Record, 301(12), 2067-2079. doi: 10.1002/ar.23961.

Yu, X., Ruan, Y., Huang, X., Dou, L., Lan, M., Cui, J. ... Shen, T. (2020). Dexrazoxane ameliorates doxorubicin-induced cardiotoxicity by inhibiting both apoptosis and necroptosis in cardiomyocytes. Biochemical and Biophysical Research Communications, 523(1), 140-146. doi: 10.1016/j.bbrc.2019.12.027.

Zaragoza, C., Gomez-Guerrero, C., MartinVentura, J. L., Blanco-Colio, L., Lavin, B., Mallavia, B. ... Egido, J. (2011). Animal models of cardiovascular diseases. Journal of Biomedicine and Biotechnology, 2011, 497841. doi: 10.1155/2011/497841. 